\title{
The effectiveness of paint remover to resin adhesive residue on base mesh of metal bracket
}

\author{
Sukarto Abubakar, Bergman Thahar, Tono S. Hambali, Jono Salim \\ Department of Orthodontic Faculty of Dentistry Universitas Padjadjaran
}

\section{ABSTRACT}

The purpose of this study is to know whether paint remover can be used to remove resin adhesive residue on base mesh of metal bracket. The study is based on in vitro experiment with descriptivecomparative and the test sample is 30 used brackets after treatment at Orthodontic Specialist Clinic Faculty of Dentistry Universitas Padjadjaran. The sample is randomly divided into 3 groups and each group consists of 10 brackets and then its bath in paint remover for 8,10 , and 12 hours, respectively and statistically analyzed with chi square $\left(x^{2}\right)$ and $\alpha=0.05$ and the results show significantly difference between resin residue before and after immersion, while resin residue after immersion its group showed there are no significant differences. Based on analyzed, it can be concluded that paint remover can be used to remove resin adhesive residue on base mesh of metal bracket and that 8,10 , and 12 hours immersion duration the result show effectiveness similiary.

Key words: Effectiveness, paint remover, resin residue

\section{INTRODUCTION}

A clinical problem that frequently occurs when a patient is undergoing orthodontic treatment is the bond failure of brackets. Its caused by several factors, such as carelessness of patients when maintaining his/her food intake, bracket position is too occlusal/incisal placed, polymerization is not perfect, adhesive material is too thick or unevenly distributed, etc. ${ }^{1}$

Although bonds can fail on any tooth at any time, certain generalizations have been made. Most failures occur at bonding visit or some time after the first bonding visit. Generaly, failure rates are related to individual teeth and to position in the arch, nevertheless bond failure more frequently occur in premolars than in incisors and canines. This is possibly because of the convex surface of premolar so the adhesive thickness is unevenly or because of the difficulty to position bracket correctly so it causes excessive occlusal force. ${ }^{1,2}$

Brackets often have to be replaced during treatment because of bond failure and, occasionally, it may be desirable to intentionally debond a bracket and replace it in a more favorable position. In an orthodontic clinic, generally to handle debonded brackets, an orthodontist may choose to: 1) prepare and reuse the same bracket, 2) bond a new bracket, 3) less frequently, place a band. ${ }^{1,3,4}$

Replacing debonded brackets with new ones may be more efficient, but for economic reason not all patients are willing to change debonded 
brackets with new ones. ${ }^{4}$ That is why an operator frequently recycle metal brackets by burning resin adhesive residue on burner and then clean and reattache them, still failure occurs frequently. It is possibly because not all resin adhesives have been removed thoroughly from brackets base in burning process so they block new resin adhesives to go through brackets base-the part that gives retention.

The main objective of recycle process is to remove resin adhesive thoroughly from the brackets base without damaging or changing neither brackets base mesh nor brackets slot size. In developed countries for instance in the United States, recycling process is done by companies like Esmadent using heating, Ortho-Cycle using chemicals, etc. ${ }^{5-7}$ but the substances and the process are kept secretly by the companies. In Indonesia, there is no company which runs brackets recycling so the process is done by operators themselves.

Metal brackets recycle can be done mechanically or chemically. Mechanical brackets recycles such as sandblasting, grinding, burning, etc. have been done a lot by researchers, whereas chemical recycle are rarely done.

Chemical solvent used for recycling/ removing resin adhesive residue from brackets base is either acid or alkaline. The acid solvent generally used is concentrated acid such as sulfuric acid, chloric acid, and nitric acid. These kinds of acids are corrosive, therefore they are not suitable for metal brackets recycling because they can change slot size and trigger corrosion. The benefit of alkaline solvent is that it does not dissolve metal so it is absolutely right to use in metal brackets recycling because it will not change neither bracket base mesh nor slot size, moreover brackets color relatively will not change. One kind of alkaline chemical solvent is paint remover.

Paint remover used in the research has several benefits such as it is effective, simple, and addition it is relatively cheap.

\section{MATERIALS AND METHODS}

This study is an in vitro experimental laboratory study with descriptive-comparative approach in which population used are edgewisestandard-metal brackets from patients of the
Orthodontic Specialist Programme Clinic Dental and Oral Hospital (RSGM) Faculty of Dentistry Universitas Padjadjaran Bandung. The sample of the study consists of 30 pieces of used brackets that meet the criteria: brackets are still in a good condition; no change in form and size; equal form and size of bracket base mesh; and there is resin residue on brackets base mesh. Samples are randomly divided into 3 groups of 10 brackets.

Prior to immersion in paint remover, brackets base mesh is examined under stereoscopic microscope with 18x zoom, afterwards it is photographed using modified Nikon (Fig. 1) and then the negatives are printed. Next the photographs are separated into 9 equal partitions and the residue of resin adhesives on brackets base mesh is counted.

The score of resin adhesive residue is counted in the opposite manner of ARI (Adhesive Remnant Index) which was introduced by Artun and Bergland ${ }^{8}$ on 4 scoring bases: Score $0=$ No resin adhesive residue on bracket base mesh; Score 1 = resin adhesive on bracket base mesh is $<1 / 2$ of bracket base mesh surface; Score $2=$ resin adhesive residue on bracket base mesh is > $1 / 2$ of the bracket base mesh surface; and Score $3=$ resin adhesive residue covering whole of the bracket base mesh surface. Scoring is done after the following process was the process of recycling by providing 30 holders ( 3 widal slides) filled with $1 \mathrm{ml}$ of paint remover solution and each bracket sample is stored in a plastic box. Next, group sample 1 is immersed in the paint remover for 8 hours, group sample 2 is immersed for 10 hours, and the third group is immersed for 12 hours. After immersion each bracket is rinsed for 5 minutes using ultrasonic cleaner to remove the remainder of the solvent and dried. After the recycling process is completed, the brackets base mesh is re-examined using stereoscopic microscope using the same procedure.

The study was conducted from June to August 2007. The photographs were taken with Modified Nikon digital camera at Metalurgy Laboratory at the Department of Mechanical Engineering Bandung Institute of Technology.

The data resulted from this research is analyzed statistically using Friedman non parametrical test with chi-square distribution $\left(\mathrm{x}^{2}\right)$ with level of reliability $95 \%(\alpha=0.05)$. 


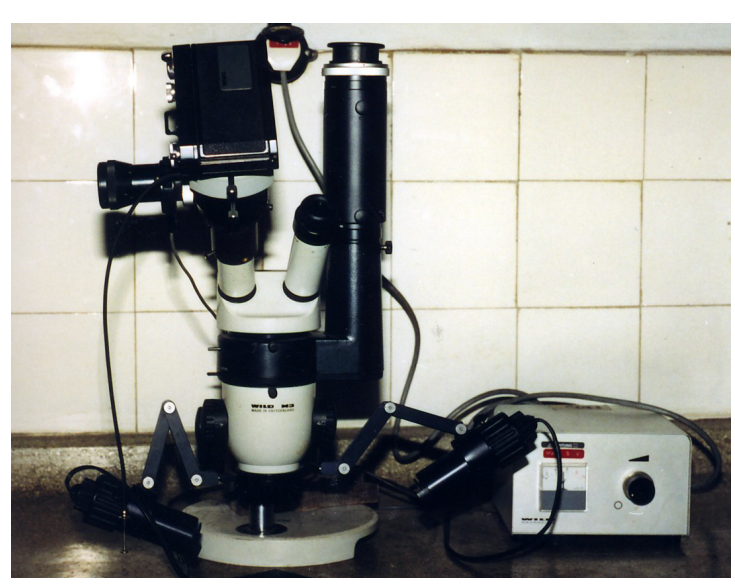

Figure 1. Stereo microscope with modified Nikon camera at Dept. Mechanical Engineering Bandung Institut of Technology.

\section{RESULT}

Table 1 shows the final result on the measurement of resin adhesive residue on 30 base mesh of metal brackets before and after immersion in paint remover. The data on Table 1 is processed by using statistical non parametrical Friedman Test and ranked in sequence as shown in Table 2.
The data in Table 2 is then statistically analyzed using chi-square distribution with $\mathrm{dk}(5)$ and level of reliability $95 \%(\alpha=0.05)$, and showed a chi-square count (42.332) greater than the chisquare table (11.070). This indicates significant difference in resin adhesive residue on the base mesh of the metal brackets before and after immersion in paint remover. The average result of the final ranking on the score of resin adhesive residue on base mesh of metal brackets before and after the immersion in paint with the three treatments implied in the above may also be shown in a block diagram as shown in Graph 1.

Based on Graph 1, the score reduction after immersion in paint remover shows 2.60 (from 4.55 to 1.95); after 8 hour immersion 3.00 (from 5.00 to 2.00); after 10 hour immersion; and 3.20 (from 5.35 to 2.15 ) after 12 hour immersion. In order to confirm that there is significant difference in the number of resin residue after and before the immersion, then, the varying result from the three different treatments in the above is tested further by ranking data on Table 1 using non parametrical Friedman Test as shown in Table 3.

Table 1. Resin adhesive-residual score assessment result in metal bracket mesh before and after bathed in the paint remover.

\begin{tabular}{ccccccc}
\hline \multirow{2}{*}{$\begin{array}{c}\text { No } \\
\text { Sample }\end{array}$} & \multicolumn{7}{c}{ Immersion time } \\
\cline { 2 - 7 } & \multicolumn{2}{c}{ 8 hour } & \multicolumn{2}{c}{ 10 hour } & \multicolumn{2}{c}{ 12 hour } \\
\cline { 2 - 7 } & Before & After & Before & After & Before & After \\
\hline 1 & 3 & 1 & 3 & 0 & 2 & 0 \\
2 & 2 & 1 & 2 & 0 & 3 & 1 \\
3 & 2 & 1 & 2 & 1 & 3 & 1 \\
4 & 1 & 0 & 3 & 1 & 2 & 1 \\
5 & 2 & 1 & 2 & 0 & 2 & 0 \\
6 & 2 & 1 & 3 & 1 & 3 & 1 \\
7 & 2 & 1 & 3 & 1 & 2 & 1 \\
8 & 3 & 0 & 2 & 1 & 3 & 1 \\
9 & 2 & 0 & 2 & 1 & 3 & 1
\end{tabular}

Table 2. Resin adhesive-residual score assessment after being ranked in metal bracket basis-mesh before and after bathed in the paint remover.

\begin{tabular}{ccccccc}
\hline & \multicolumn{7}{c}{ Immersion Time } \\
\cline { 2 - 7 } & \multicolumn{2}{c}{$\mathbf{8}$ hour } & \multicolumn{2}{c}{ 10 hour } & \multicolumn{2}{c}{ 12 hour } \\
\cline { 2 - 7 } & Before & After & Before & After & Before & After \\
\hline Rank total & 45.50 & 19.50 & 50.00 & 20.00 & 53.50 & 21.50 \\
Rank mean & 4.55 & 1.95 & 5.00 & 2.00 & 5.35 & 2.15 \\
$\mathrm{n}$ & 10 & 10 & 10 & 10 & 10 & 10 \\
\hline
\end{tabular}




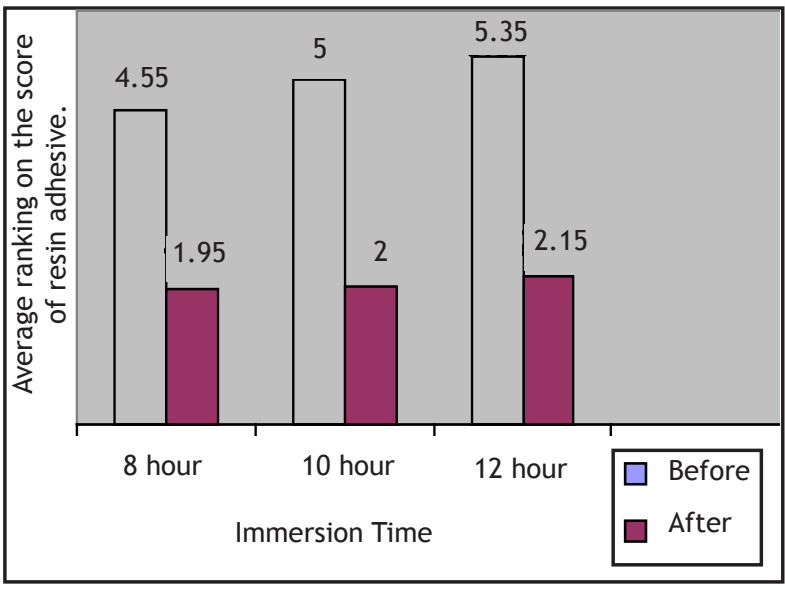

Graphic 1. Resin adhesive-residual score average assessment after being ranked in bracket basis-mesh before and after bathed in the paint remover.

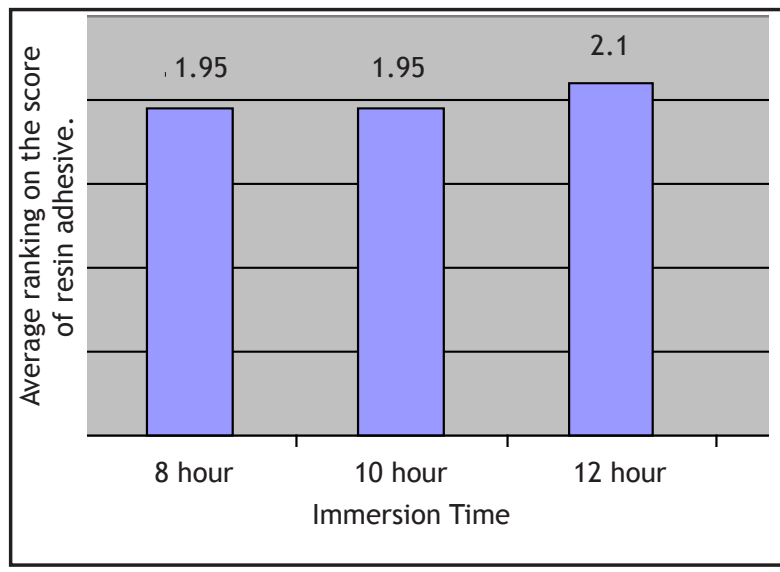

Graphic 2. Resin adhesive-residual score assessment after being ranked in metal bracket basis-mesh and after recycled with three treatments (Resin adhesive-residual score ranking average after the bathing).

Table 3. Resin adhesive-residual score assessment after being ranked in bracket basis-mesh after bathed in the paint remover by three treatments (Bathing time, ranking amount, ranking average, sample amount).

\begin{tabular}{cccc}
\hline Immersion time & Rank total & Rank mean & Total sample \\
\hline 8 hour & 19.50 & 1.95 & 10 \\
10 hour & 19.50 & 1.95 & 10 \\
12 hour & 21.00 & 2.10 & 10 \\
\hline
\end{tabular}

A

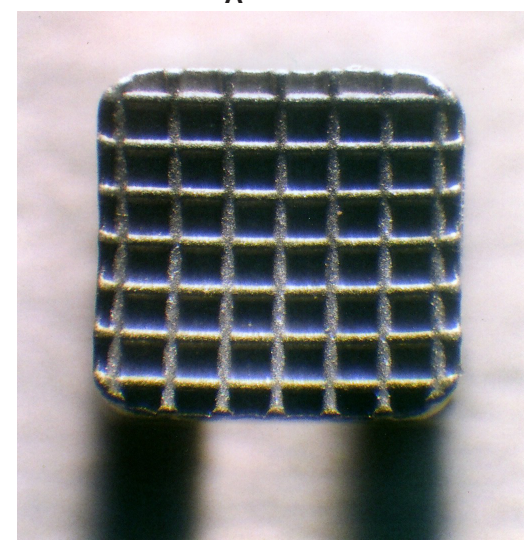

B

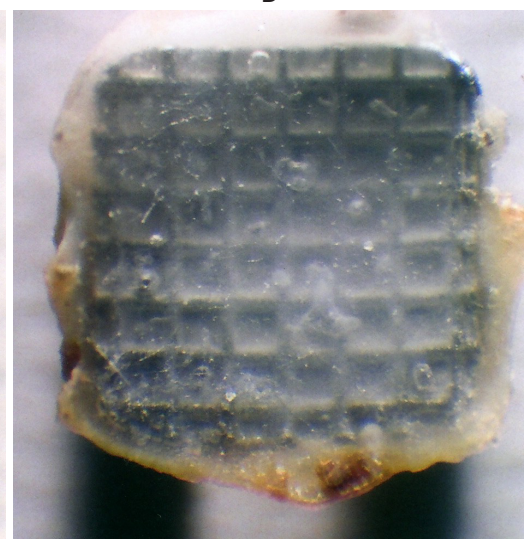

C

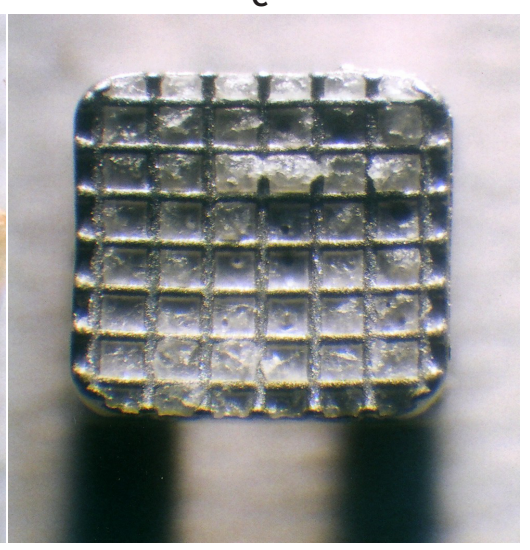

Figure 2. Resin-residual in bracket basis-mesh before and after the bathing. A) New metal bracket basis-mesh; B) Resin adhesive residual that is adhered in metal bracket basis-mesh before the bathing; $\mathrm{C}$ ) Resin adhesive residual after being bathed in the paint remover.

The data in Table 3 can also be shown in Graph 2. In Graph 2, the average difference between resin residue score before and after immersion is shown. Again, in order to confirm whether the difference is significant or not, then, the data is tested using chi-square distribution with $d k(2)$ and level of reliability 95\% ( $\alpha=0.05)$ and is resulted in chi-square count $(0.333)$ less than chi-square table (5.991). This shows that there is no significant difference between of resin adhesive residue of the metal brackets after the three different treatments.

\section{DISCUSSION}

The problem that frequently occurs during orthodontic treatment is bond failure. It may happen between resin and brackets base (adhesive), between resin and resin (cohesive), or between resin and email (adhesive). According to Zachrisson ${ }^{9}$, this problem never occurs in a manner that it is pure adhesive or totally cohesive. The 
incidence of bond failure acording to Wang and $\mathrm{Lu}^{10}$ between brackets base and resin is $43-49 \%$, resin and resin is $12-24 \%$, and resin and the surface of teeth is $32-40 \%$. The lack of adhesiveness between brackets base and resin is due to the stress which is concentrated on brackets base and defect on the resin layer. Therefore, it is compulsory to make sure that there is proper adhesion between brackets base and resin. ${ }^{11,12}$

The bond failures, Zachrisson ${ }^{9}$ argues, is caused by four main factors: Moisture contamination (gingiva fluid, saliva); Forces exceeding the bond strength (too heavy ligation, sudden impact forces of mastication and oclusion, trauma); Inadequate adaptation of bracket to tooth surface of the teeth (judged from an uneven or thick layer of adhesive on the contact surface of several loose brackets); and individual variation (hypersalivation, differences in email composition and response to etching, rebonded brackets).

Bonding orthodontic brackets to teeth has been a common procedure for more than 25 years, however the bond failure of the brackets is not less common. Therefore, this failure should be anticipated so that the treatment will run successfully. ${ }^{1,13}$ One procedure among many others to overcome this problem is to recycle the brackets, either by the manufacturer or by the operator. Recycled orthodontic brackets may be used in the clinic for several reasons, for example, to allow patients to reduce cost. Until recently, brackets recycling is still in controversy since it may cause and spread infection, bond failure, or ligitation. ${ }^{4}$ However, this recycling process is frequently carried out by orthodontical practitioners as is shown in a survey by British Orthodontic Society on 300 of their members. The survey shows that $47.5 \%$ of the total respondent recycle metal brackets, and more specialist practitioners than consultants did so. ${ }^{14}$

The purpose of this study is to know whether paint remover can be used to remove resin adhesive residue on base mesh of metal bracket. This study is an in vitro and there has never been any research on brackets recycling by using paint remover, therefore this research can not be compared with other results. In addition, the chi-square distribution test shows that paint remover can be used to remove resin residue on base mesh of metal bracket. At the duration of 8 ,
10 and 12 hours of immersion, the chi-square test indicates that the difference is minuscule.

After immersion, the brackets base mesh when seen with naked eyes, of course, appears clean. However, when using stereoscopic microscope with $18 \mathrm{x}$ zoom, the resin residue is considerably conspicuous, especially on the surface of the brackets base. This indicates that further research is necessary. In order to completely remove resin residue from the surface of the mesh brackets base, it is either to extend the immersion time or to apply high-pressured air spray on the brackets base mesh.

\section{CONCLUSION}

In conclusion, when used on brackets base mesh with chi-square distribution at $n=30$ and $p=0.05$, the effectiveness of the paint remover at the durations of 8,10 , and 12 hours of immersion is equally effective to remove the resin adhesive residue on the brackets base mesh.

\section{REFERENCES}

1. Egan FR, Alexander SA, Cartwright GE. Bond strength of rebonded orthodontic brackets. Am J Orthod Dentofac Orthop 1996;109(1):6470.

2. Kinch AP, Taylor H, Warltier R, Oliver RG, Newcombe RG. A clinical trial comparing the failure rates of directly bonded brackets using etch times of 15 or 60 seconds. Am J Orthod Dentofac Orthop 1988;94(6):476-83.

3. Bishara SE, Laffoon JF, Von Wald L, Warren $J$. The effect of repeated bonding on the shear bond strength of different orthodontic adhesives. Am J Orthod Dentofac Orthop 2002;121(3):521-5.

4. Dawjee S, Gheevarghese 0 . Recycling debonded brackets with an acid bath. J Clin Orthod 2004;XXXVII(11):605-6.

5. Buchman DJL. Effects of recycling on metallic direct-bonding orthodontic brackets. Am J Orthod 1980;77(6):654-68.

6. Mascia VE, Chen SR. Shearing strengths of recyled direct-bonding brackets. Am J Orthod 1982;82(3):211-6.

7. Wright WL, Power JM. In vitro tensile bond strength of reconditioned brackets. Am J 
Orthod 1985;87(3):247-52.

8. Artun J, Bergland S. Clinical trial with crystal growth conditioning as an alternative to acidetch enamel pretreatment. Am J Orthod 1984;85(4):333-40.

9. Zachrisson BU. A posttreatment evaluation of direct bonding in orthodontics. Am J Orthod 1977;71(2):173-89.

10. Wang WN, Lu TC. Bond strength with various etching times on young permanent teeth. Am J Orthod Dentofac Orthop 1991;100(1):72-9.

11. Smith DC, Maijer R. Improvements in bracket base design. Am J Orthod 1983;83(4):277-81.
12. Wang WN, Li CH, Chou TH, Wang DDH, Lin $\mathrm{LH}$, Lin CT. Bond strength of various bracket base designs. Am J Orthod Dentofac Orthop 2004;125(1):65-70.

13. Sorel O, Alam RE, Chagneau F, Cathelineau G. Comparison of bond strength between simple foil mesh and laser-structured base retention brackets. Am J Orthod Dentofac Orthop 2002;122(3):260-6.

14. Huang TH, Yen CC, Kao CT. Comparison of ion release from new and recycled orthodontic brackerts. Am J Orthod Dentofac Orthop 2001;120(1):68-75. 